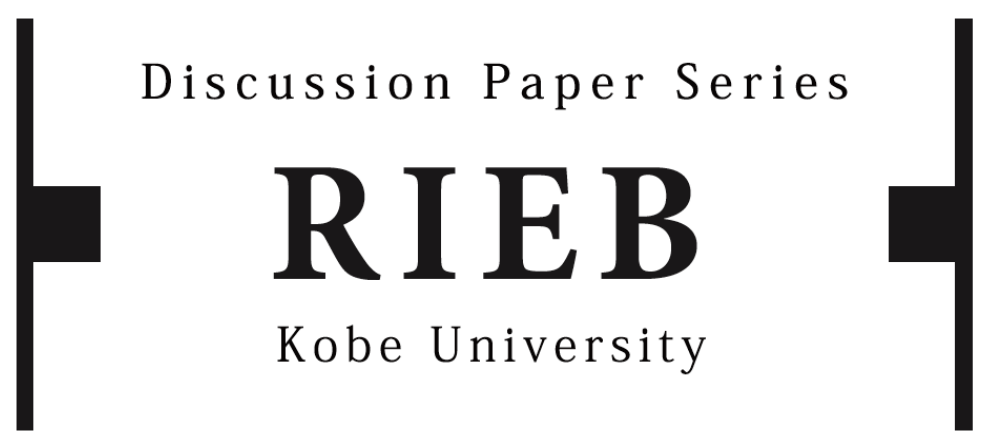

DP2010-31

Achieving equity in health through community based health insurance: India's experience with a large CBHI programme

Aradhna AGGARWAL

November 10, 2010

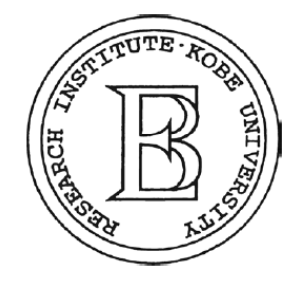

Research Institute for Economics and Business Administration

Kobe University

2-1 Rokkodai, Nada, Kobe 657-8501 JAPAN 


\title{
Achieving equity in health through community based health insurance: India's experience with a large CBHI programme*
}

\author{
Aradhna Aggarwal \\ Current affliation: Visiting Professor, \\ Research Institute of Economics and Business, \\ Kobe University, 2-1, Rokkodai-cho, Nada-ku, Kobe \\ 657-8501 JAPAN \\ Tel: 81-78-803-7270; Fax: 81-78-803-7059 \\ Parent affiliation: Associate Professor \\ Department of Business Economics \\ South Campus, University of Delhi \\ Benito Juarez Road, Delhi-110021 \\ Telefax: 91-11-24111141 \\ aradhna.aggarwal@gmail.com
}

\begin{abstract}
This paper analyses equity in one of the largest community based health insurance programme in India: Yeshasvini, run by the Department of Cooperation in Karnataka, a state in India. The analysis is based on a primary survey of 4109 households in rural Karnataka. The study covers various dimensions of vulnerability and assesses their relationship with enrolment, renewal of enrolment, and utilisation of health care services using logistic regression techniques. The results demonstrate that inequities do exist. However, they are less pronounced in the distribution of benefits than in enrolment and renewals. The study argues that while CBHI may be used as a mechanism to reach the most disadvantaged population groups, they can not be considered as substitute for government created health infrastructure.
\end{abstract}

Key words: Community-based health insurance (CBHI) Karnataka state India, Equity, Gender, vulnerability

JEL: I18

* This paper is a part of a larger study assessing health and economic effects of Yeshasvini health care programme in rural Karnataka. I would like to thank the 'Bill \& Melinda Gates Foundation' for funding this study. I would take this opportunity to thank the Global Development Network (GDN) for giving me an opportunity to carry out this study. I am indebted to Mr. Ravi Kumar and Mr. S.R.Naik of the Department of Cooperation of Karnataka government and officials from various Departments of the State Government for providing relevant data and information. An earlier version of the paper was presented at the British Northern University, India Forum (BNUIF) seminar "India's Service Sector: Who does it serve?" Hyderabad 24-26 March, 2010. I would like to thank the participants and discussant for their useful coments and suggestions. 


\title{
Achieving equity in health through community based health insurance: India's experience with a large CBHI programme
}

\begin{abstract}
This paper analyses equity in one of the largest community based health insurance programme in India: Yeshasvini, run by the Department of Cooperation in Karnataka, a state in India. The analysis is based on a primary survey of 4109 households in rural Karnataka. The study covers various dimensions of vulnerability and assesses their relationship with enrolment, renewal of enrolment, and utilisation of health care services using logistic regression techniques. The results demonstrate that inequities do exist. However, they are less pronounced in the distribution of benefits than in enrolment and renewals. The study argues that while CBHI may be used as a mechanism to reach the most disadvantaged population groups, they can not be considered as substitute for government created health infrastructure.
\end{abstract}

\section{The study}

The new international thinking on health that emerged during the late 1990s underlines the notion that the governments in developing countries should promote and strengthen community based health insrance $(\mathrm{CBHI})$ schemes $^{1}$ as a viable option in providing financial protection to the poor (WHO 2000, 2001) ${ }^{2}$. As a result, governments in many developing countries have taken initiatives to strengthen these schemes as part of their health policy. This has led to proliferation of these programmes across developing countries (ILO 2005, Tabor 2006 for survey). There is evidence albeir weak that such schemes help to improve financial access, utilisation, and quality of health care services through cooperative and community efforts (See, e.g. Aggarwal 2010 for a recent study). However, there is a gap in knowledge in determining how equitable such schemes are. While examining the issue of equity, most studies focus on the socio economic composition of the current members of these schemes. Generally it is believed that for equity reasons, membership should not be biased towards the

\footnotetext{
${ }^{1} \mathrm{CBHI}$ schemes are known by different names in different parts of the world, including: microinsurance, community health finance organisations, mutual health insurance schemes, pre-payment insurance organisations, voluntary informal sector health insurance, mutual health organisations/associations, community health finance organisations, and community self-financing health organisations.

${ }^{2}$ The Commission on Macroeconomics and Health (WHO, 2001), for example, recommended that, "out-of-pocket expenditures by poor communities should increasingly be channeled into community financing schemes to help cover the costs of community-based health delivery"(p 60).
} 
better off and be effectively open to economically vulnerable groups. Thus, most studies have linked equity with income or wealth. However, equity aspects of a programme cannot be assessed in terms of its ability to address economic vulnerability alone. In the recent literature, multi dimensional measures of vulnerability are emerging. In a broader sense, vulnerability is defined (Schmidt-Thomé and Jarva, 2003) as a set of conditions and processes resulting from physical, social, economic, locational and environmental factors, which determine the susceptibility of an individual/community to the impact of catastrophic events (deterioration of health in the present context). In the existing literature on equity in micro health insurance, however, vulnerability arising out of economic factors occupies a central place while other dimensions of vulnerabilities are relatively overlooked. Further, most studies have focused on the composition of current members by economc category; a few have examined the characteristics of those who have been renewing registration or have actually been the claimants of the benefits. The present study addresses these gaps in the literature. The main aim of the study is to examine, using a broad based concept of vulnerability, equity in enrolment, renewal of membership, and utilisation of services in the context of one of the largest CBHI programmes in India: Yeshasvini Health Care programme. The programme offers the rural poor an opportunity of taking benefits of advanced and highly expensive surgical treatments which otherwise would be non accessible to them. This study examines whether the programme reaches out to the most vulnerable sections of the rural poor. The multi-dimensional concept of vulnerability used in the study covers:

- social vulnerability,

- gender-specific vulnerability,

- health vunerability,

- economic vulnerability, and

- location specific vulnerability 
The rest of the study is planned as follows. Section 2 provides a theoretical discussion on equity dimensions of CBHI. Section 3 focuses on the Yeshasvini programme. It describes the core characteristics of the programme and discusses their implications for equity. Section 4 provides a theoretical framework which Section 5 describes the research designs and database. Section 6 discusses the empirical results. Finally, Section 7 concludes the analysis.

\section{CBHI and health equity: Theoretical discussion}

The theoretical explanations for the success of CBHI are set within the fold of the social capital framework (Atim, 1999, Jakab and Preker 2001, Dror and Preker 2002, Criel and Waelkens, 2003, Dror and Preker, 2002, 2004, Hsiao, 2001, Jowett, 2003, 2008, KiwanukaMukiibi et al.2005, Meessen et al, 2002, Ron, 1999, Schneider, 2004, Zhang et al., 2006) ${ }^{3}$. Low-income households are generally benefited by informal risk protection through family and relatives, community links, institutional links or societal links. These social and community links, if institutionalised through insurance programmes, may serve as social capital and can effectively play an important role in promoting social welfare (Dror and Preker 2002, p. 48). Social connections as well as trust and local community control over these prorammes overcome the informational disadvantages and high transaction costs involved in providing insurance to low income population. This in turn improves willingness to pay even by the poorest of the poor. Further, communities are set within highly different economic, cultural, demographic, political and epidemiological contexts. One major advantage of micro- insurance is that their technical designs are heavily influenced by these factors. This offers considerable flexibility to the parties negotiating a contract, reducing

\footnotetext{
${ }^{3}$ Mladovsky and Mossialos (2008) however use the social capital framework to argue how the same factors may affect the growth of CBHI adversely.
} 
transaction costs and scaling up participation (Churchill 2006). Thus, social bonding, solidarity, trust, intra- and extra-community networks, vertical civil society links and statesociety relations at the local level are important factors in explaining the success of the CBHI in reaching out to the poorest. Theoretically, therefore, CHI schemes may be an effective mechanism for ensuring equitable distribution of health protection among the rural population in the resource-poor settings where governments have limited financial and institutional capacity.

The above arguments notwithstanding, evidence indicates that there have been wide variations in the performance of these schemes. Some CBHIs have played a useful risk protection role and complemented public health care efforts (see, Tabor 2006 among others) by extending social protection to the most vulnerable sections that would otherwise have no financial protection against the cost of illness. But, many others have failed. In their review of literature on equity, Preker et al (2002) and Jakab and Krishnan (2004) find that while CBHI is effective in reaching the low income group people, the poorest and socially excluded groups are not automatically included. This exclusion effect is observed by Ekman (2004) also. The most important reason turns out to be the poor ability to pay followed by the distance from the providers. Using cluster randomised controlled trial over 2003-05, Ranson et al (2007) evaluated the impact of after-sales-service with supportive supervision and prospective reimbursement on the uptake of benefits of a community based health insurance scheme (SEWA) in India by its poorest members. However, time and information dissemination measures were not found to be sufficient to ensure the poorer members a greater share of the scheme benefits. In contrast, Onwujekwe et al. (2009) and Polonsky et al (2009) found strong evidence of equity in CBHI schemes in Nigeria and Armenia, respectively. While analysing equity dimensions of two CBHI programmes in Nigeria, 
Onwujekwe et al. (2009) suggested that there was no inequity in enrolment, willingness to renew registration and utilisation of services. The analysis was based on the data collected using a questionnaire that was administered to 971 respondents in two communities, selected by simple random sampling. Polonsky (2009) evaluates equity of Oxfam's CBHI schemes in rural Armenia. Members of a random sample of 506 households in villages operating insurance schemes in rural Armenia were interviewed using a structured questionnaire. Logistic and Poisson regression analyses were performed to identify the determinants of health facility utilisation across socio-economic strata. Its findings demonstrate that the distribution of benefits among members of this community-financing scheme is equitable. Apparently, the equity effects of CBHI scheme are expected to vary across countries, and CBHI types and designs; and are subject to empirical analysis. In a qualitative investigation of demand for health insurance in rural West Africa, De Allegri et al (2006) suggest that the success of a CBHI programme largely depends on its technical design. The present study thus focuses on the "Yeshasvini" health care programme in India and analyses its equity dimensions.

\section{Core Characteristics of Yeshasvini and Their Implications for Equity}

\section{Organisational Characteristics}

The scheme was introduced in June 2003 in "Karnataka", an Indian state by the Department of Cooperation (DOC) to provide insurance cover to members of cooperative societies in rural Karnataka (Kuruvilla 2005, Radermacher et al 2005, and ILO 2006). While the programme is being run under the auspices of a government department, it is governed by an independent charitable trust: "Yeshasvini Cooperative Farmers' Health Care Trust". The 
Trust consists of 12 members and is chaired by the Principal Secretary of the Department for Cooperation. Other members include employees of the Karnataka Department of Cooperation; health professionals representing network hospitals; and the Director of the Health Department ${ }^{4}$. The Trust has hired "Family Health Plan Limited" (FHPL), a TPA registered with "Insurance Regulatory and Development Authority" to administer the scheme. The vast administrative infrastructure of the DOC has facilitated the collection of revenue at no additional cost. Its involvement ensures government backing of the scheme and proves to be an important trust building factor for the programme. Further, access to the cooperative network assists the managers of the programme in mobilising membership and implementing the scheme at the grassroots level with the help of cooperative societies. Cooperative societies organise farmers and other informal sector workers in rural areas in an institutional framework and act as a communication channel between the government and the rural population. There were a total number of 32900 Co-operative societies in Karnataka in 2007. Of them, 28099 co-operatives were actively working. These societies not only mobilise membership but also extend help to members in seeking treatment from network hospitals.

The designated health care providers in the scheme are mainly private hospitals, although charitable, public sector and cooperative sector hospitals are also participating in the scheme. Some are super specialty hospitals. In 2008-09, the number of network hospitals was 349 . These were spread across 27 districts. The Trust has fixed a price for each surgery, including nearly all connected costs. An important feature of the programme is that the price for surgery paid to a network hospital is significantly below the normal market charges and a well specified list of exclusions is provided to all the hospitals.

\footnotetext{
${ }^{4}$ Included as the $12^{\text {th }}$ trustee in November 2005.

${ }^{5}$ Third Party Administrators (TPAs) are for-profit-companies that assume most of the administration of an insurance scheme in exchange for a commission. The TPA's main duty is to manage the contact between the client, the health care provider and the insurance scheme.
} 
Thus, the Trust is benefited by the government administrative machinery, provisions of private health care services, and values and institutional infrastructure of the cooperative societies.

\section{Technical design}

Low contribution: The premium was fixed at Rs 120 per year per person. Recently, it has been raised to Rs 130. A rebate of $15 \%$ is offered on contribution for families of five or more members.

Long enrolment schedules: Enrolment schedules are extended to 5 months namely, January to May. These months are also the harvesting time of cash crops such as cotton and sugarcane which make it easier for farmers to make the payment.

Flexible mode of payment: The mode of payment is not fixed either. It is decided by the local cooperative societies depending on the local conditions. Some societies accept monthly payments during the enrolment period while others demand lump sum payment. Recognising that the subscription may be financial obstacle to membership, some societies accept bimonthly payment also. Credit cooperative societies generally deduct the subscription amount with the consent of the member while lending money.

Attractive sevice package: The benefit package is well defined and well designed focusing on high cost surgery events that could be catastrophic for the poor households. Free OPD consultations and diagnostic lab tests at concessional rates are optional. The maximum 
coverage per person per year amounts to Rs. 200,000 with free OPD. The benefits are reviewed from time to time and appropriate changes are introduced in the package depending on the demand. For instance, recently, normal deliveries and emergencies such as snake bite, bull gore and dog bites are also included in the package, keeping in view the growing demand for such coverage.

Cashless transactions: An important feature of this scheme is that the procedures are minimised and transactions are cashless. Paients are not involved in any administrative process.

Enrolment process for network hospitals: A hospital willing to join the Network can apply if it has 25 or more beds. It is given a self assessment form to assess itself. Each medical facility provided by the hospital is assigned specific marks in this form. A minimum of 88 marks is to be scored to be part of the network. Hospitals claims are verified through inspections by the Trust before making the final decision of its enrolment.

Monitoring of network hospitals: The FHPL undertakes regular inspections of networkhospitals to monitor the quality of their services, and to ensure that the latter remain adhered to their commitments made to the Trust. If they are found defaulting, strict actions are taken against them including permanent ban on their yeshasvini membership.

Financial sustainability: At the current level of premium, financial sustainability is not achievable even with a vast membership base. This is because it covers high end medical treatment. In order to augment its resources, the Trust welcomes donations from private and government bodies. It has also been decided to collect 3 percent of the profits from the 
profitable societies as donations. Furthermore, the management has created a contingency fund which is invested in interest yielding assets to earn interest income. Finally, the scheme receives government subsidy. A part of this is added to the contingency fund. The capacity of managers to manage funds has thus ensured the financial sustainability of the scheme.

\section{Achievements}

Large membership base: Yeshasvini Health insurance programme has effectively created a large membership base. In the first year of the scheme itself 1.6 million cooperative members enrolled with the scheme. In 2008-09, enrolment increased to 3.0 million which marked 29.3 percent increase over the increased base of the last year.

Broad based use of services: There has been a rapid increase in the number of surgery cases. In absolute terms, in 2007-08, a total number of 60,668 surgeries took place. In 2009, during April-October alone 23,883 sureries had been perromed under the programme. A wide range of surgical processes are being offered by the scheme. Heart, gynae, general, Uro, Optho, ENT and Ortho surgeries accounted for 85 percent of the total surgeries performed over the period of three years, 2003-04 to 2006-07. Heart surgeries accounted for almost 20 percent of total surgeries followed by general and OBG surgeries.

Spatial dispersion of service providers: There has been a considerable change in the distribution of beneficiaries by location within a short span of time (Table 1). In 2004-05, five of the 27 districts: Mandya, Kolar, Hassan, Bangalore and Davangere accounted for almost half the beneficiaries. The level of concentration declined sharply within the next two years. The $\mathrm{HH}$ index of concentration of claimants was 670 in 2004-05, it fell to 323.3 in 2006-07. 


\section{INSERT TABLE 1 HERE}

In 2004-05, 148 hospitals registered 17,407 surgeries under Yeshasvini. Of this, 1700 (9.81 percent) were performed in Narayana Hrudayala hospital alone. In 2006-07, 290 hospitals registered Yeshasvini patients and the $\mathrm{HH}$ ratio declined from 254 (in 2004-05) to 230. Spatial distribution of hospitals performing surgeries under the programme also showed a remarkable change. In 2006-07, hospitals across 79 cities participated in the process and the HH index declined steeply.

In nutshell, the programme has developed mechanisms to tap the government for its vast administrative machinery to mobilise members and monitor the scheme without creating additional administrative infrastructure; the private sector for quality health care services; and the cooperative sector networks for the societal capital generated over the years through business linkages between these societies and their members. The synergy developed at various levels is directed to finance high cost medical treatment of the poor who otherwise have no health security provided by the State. It is designed and managed by professionals who have developed well specified procedures for enrolment, networking of hospitals, treatment and claim settlement. There are mechanisms to monitor the operations of various actors and punish the defaulters. As a result, Yeshasvini Health insurance programme has effectively created a large membership base and has successfully been providing services across the state. The fixed rates of surgery, tight monitoring and the possibility of punitive actions discourage over-utilisation of health care services, both on the demand and supply side. The institutional, organisational and technical features of the programme, and its success in creating a wide membership and effective service provisions are expected to ensure that the scheme is equitable. 


\section{Determinants of enrolement, renewals and claims: Theoretical Model}

People purchase health insurance if the utility of the expected benefits of coverage, in the form of expected covered expenditures plus the value of protection from financial risk, exceed the premium. Algebraically, let $U_{N}$ be the utility from not obtaining insurance, such that

$$
\mathrm{U}_{\mathrm{N}}=\mathrm{U}_{\mathrm{N}}\left(\mathrm{Y}_{\mathrm{N}}, \mathrm{M} ; \mathrm{T}_{\mathrm{w}}\right)+\mathrm{e}_{\mathrm{N}}
$$

where, $Y_{N}$ is income in the uninsured state, $M$ are out-of-pocket medical expenses when uninsured (assumed to be zero when insured), $T_{w}$ is a shift variable capturing the addition to utility from non-participation for individuals with weak preferences for coverage, and $\mathrm{e}_{\mathrm{N}}$ is a stochastic error term. Similarly, let Ui be the utility from insurance

$$
\mathrm{U}_{\mathrm{I}}=\mathrm{U}_{\mathrm{I}}\left(\mathrm{Y}_{\mathrm{I}}, \mathrm{P} ; \mathrm{T}_{\mathrm{s}}\right)+\mathrm{e}_{\mathrm{I}}
$$

It depends upon income in the insured state, premium $\mathrm{P}$, a shift factor, $\mathrm{T}_{\mathrm{s}}$, accounting for the gain in utility from enrolling in health insurance, and error term $\mathrm{e}_{\mathrm{I}}$. Out-of-pocket medical expenses are assumed to be zero in the insured state.

An individual will enroll if $\mathrm{U}_{\mathrm{I}}\left(\mathrm{Y}_{\mathrm{I}}, \mathrm{P} ; \mathrm{T}_{\mathrm{S}}\right)-\mathrm{U}_{\mathrm{N}}\left(\mathrm{Y}_{\mathrm{N}}, \mathrm{M} ; \mathrm{T}_{\mathrm{w}}\right)>\mathrm{e}_{\mathrm{N}}-\mathrm{e}_{\mathrm{I}}$. The difference is a linear function of $\mathrm{Y}, \mathrm{P}, \mathrm{M}$ and the difference in tastes for coverage, $\mathrm{T}_{\mathrm{s}}$, and $\mathrm{T}_{\mathrm{W}}$. Thus

$$
\text { Enrolment }=f\left(\mathrm{Y}, \mathrm{P}, \mathrm{M}, \mathrm{P}_{\mathrm{f}}\right)
$$


Where $\mathrm{P}_{\mathrm{f}}=\mathrm{T}_{\mathrm{S}}-\mathrm{T}_{\mathrm{W}}$ and denotes individual preference. Assuming $\left(\mathrm{e}_{\mathrm{N}}-\mathrm{e}_{\mathrm{I}}\right)$ to be logistically distributed, coefficient estimates will be derived from logit estimates of the likelihood of enrollment.

Theories of optimal risk taking behavior suggest that households which are more likely to face vulnerability exhibit a higher coefficient of risk aversion (Lin 2009) and hence greater preference for insurance. In the above model, Y represents economic vulnerabilities (income, wealth, income sources) while $\mathrm{M}$ is a function of health related vulnerabilities (age and family health background, sanitaition conditoions, natural calamities). Individual preference are determined by socio-cultural and location specific factors. Socio-cultural factors cover, social vulnerabilities (such as social exclusion, lack of education, poor access to information, gender bias); and family size. Location specific factors on the other hand cover locational vulnerabilities (health and transport infrastructure); presence of cooperative societies; and the quality of governance. Thus, our model is

$$
\text { Enrolement }=f(\mathrm{E}(.), \mathrm{H}(.), \mathrm{G}(.), \mathrm{S}(.), \mathrm{L}(.), \mathrm{Z}(.))
$$

where $\mathrm{E}, \mathrm{H}, \mathrm{G}, \mathrm{S}$, and $\mathrm{L}$ represent economic, health, gender specific and locational vulnerabilities, respectively; and $\mathrm{Z}$ represents other variables represnting individual preferences. The same set of factors is also likely to influence renewals and the utilisation of health care services. Besley (1989) argues that just as demand for health services is derived from demand for health, demand for health insurance is derived from demand for health services. Thus the same set of factors is expected to affect the utilisation of health care and health insurance. 
Commercial health insurance cannot result in socially optimal distribution of insurance and is found to be negatively related with vulnerabilities. Our major hypothesis here is that micro insurance removes obstacles to obtaining health insurance coverage for the vulnerable population and hence is positively related with vulnerabilities. The most basic vulnerability is the existence of health vulnerability i.e. ill-health, disease, and disability. Commercial insurance imposes restrictions on insurance policies in terms of waiting periods, pre-existing condition exclusions, and cost sharing requirements that impede consumers in poor health from obtaining insurance. CBHI programmes however do not pose any such conditions. A second vulnerability arises from economic disadvantage. People with low incomes are especially price-sensitive in their purchase of health coverage. Small premiums in CBHI programmes however make insurance affordable for the poor. A third type of vulnerability arises from race or ethnicity. In part, the disadvantages associated with race or ethnicity are due to poverty and low income. Yet, potential discrimination based on race/ethnicity can also pose complex barriers to insurance coverage. Socially vulnerable groups such as women, and people with low education and poor access to information may also face important barriers to effective and informed decision-making. $\mathrm{CBHI}$ in particular Yeshasini operates at the grassroot level and involves cashless transctions to remove such obstacles. Finally, locational vulnerabilities such as poor health and transport infrastructure make people vulnerable to catastrophic shocks. A sparse supply causes inequity in access to services but at the same time insufficient supply of health services may well be an inefficient reaction to insufficient demand. Weak demand may not be linked with slight ability to pay but due to the prevalence of barter transactions in a predominantly monetised economy. Microinsurance has the potential of breaking this vicious circle by generating demand for health care, which, in turn, could improve supply (Dror and Jacquier, 1999). As seen above, Yeshasvini has large membership base with vast network of health service providers spread across the state. 
Finally, the programme's success in building the atmosphere of trust and transparency is expected to have contributed to the willing to pay by the poor. Thus, we hypothesise that a large community based insurance programme offers a viable insurance option for the vunerable population.

\section{Model Estimation and database}

In an attempt to estimate Model (1), we express both dependent and independent variables in terms of quantifiable variables. These are as follows.

\section{Dependent:}

Enrolment $=1$, if a atleast one memberof the household is enrolled with the programme $=0$, otherwise;

Renewal $=1$ if at leastone member of the household has been member of the programme for the pat three years

$$
=0 \text { otherwise; }
$$

Claimant/Beneficiary= 1 if at least one member of the household has claimed benefit in the past three years.

$=0$.

\section{Independent:}

Economic vulnerabilities: Economic vulnerabilities are captured by the following income related variables: 
Annual income (annual_inc) : Annual household income

Concen_inc : HH index of concentration of income sources

Household wealth indices (hh_wealth) : Wealth indices based on ownership of assets were generated using principal components analysis.

Health vulnerabilities: The likelihood of a health shock may vary systematically with observable characteristics, such as age, prevalence of chronic health problems, and ecological and sanitation conditions in the surroundings in which households live. Age is captured by two variables:

Headage: Age of the head of the family

Age_dividend: proportion of household members in the working age group.

The prevalence of chronic health problem is represented by a dummy, chron_health: $=1$ if at least one member is suffering from chronic health problem. $=0$, otherwise .

Ecological and sanitation conditions are proxied by,

V_wat_san: Index of living conditions (measured by principle component analysis), and

V_Naturalcdn: No. of beneficiaries of natural disaster as percentage of total population

Gender vulnerability Sh_female: Share of female members in the household 
Social vulnerability: These are captured by the following variables

SC_group: $=1$ if belongs to SC/ST

$=0$, otherwise

Aveduyears: average education years of the household

Access_TV: regularity of watching TV on likert scale of 1 to 4

Access_Paper : regularity of reading newspaper on likert scale of 1 to 4 .

Membershg: $=1$ if member of Self help groups (SHGs)

$=0$ otherwise

Locational vulnerabilities: Village specific, and district specific health attributes along with household specific characteristics are used in the study to capture locational vulnerability. They include health infrastructure, distance from the nearest health facility, and distance from the nearest yeshasvini facility, prevalence of natural calamities, and water and sanitation conditions.

V-hlthinfra : Index of health facilities created using the principal component analysis (PCA)

V-hlthdistance: Distance from the nearest health facility

Y-dist : distance of the nearest Yeshasvini facility

D_ healthinfra : Index of the quality of district level health infrastructure

D-tpt: PCA based index of district level transport facilities

\section{Control variables:}

Size: Household size

D_R_f_rat : rural female literacy rates

D_f_m_gp: female membership gram panchayats as ratio of total members 
V_copop : cooperative societies per capita

D_pcy : per capita income at the district level

In general, the model is specified as:

$$
\mathrm{Z}=\beta \mathrm{X}+\mathrm{U}
$$

where Ui is a stochastic error term. The models estimated are of discrete choice type, which explain the probability that a person chooses to enroll, renew membership and utilize the programme benefits in alternative specifications, in terms of the variables representing household specific characteristics, and the socio-economic-health environment in which the population lives. Logit regression methods were employed for estimation of the specified functions. The binary logistic regression model is stated in terms of the probability that $\mathrm{Y}=1$ given $\mathrm{X}$.:

$$
P(Y=1 \mid X)=\frac{-}{1+\exp (-X / O)} \quad[1]
$$

The probability that the household is member/claimant is given by:

$$
\text { Probi }=\operatorname{Pr}[\mathrm{P} 0 \mathrm{i}=1 \backslash \mathrm{Xi}]=\operatorname{Pr}[\mathrm{Ui}<\beta 1 \mathrm{Xi}]=\theta[1-\beta 1 \mathrm{Xi}
$$

Where $\mathbf{X}=$ a vector containing all the independent variables.

Secondary and primary data sources were used to create a database for the study. The database contained three levels of hierarchy: district level; village level and the household level.

Household data: Primary data were collected through fully structured household questionnaires in 82 villages drawn from a sample of 16 districts in Karnataka. A total of 4109 households were interviewed during the months of December 2007 to May 2008. A multi-stage stratified design was adopted for the survey for deriving the coverage. 
Village level data: The village level information was collected through primary and secondary sources. The 'Department of Rural Development and Panchayat Raj' maintains vast information system on the basic amenities available in the villages of Karnataka. We compiled this information for 82 sample villages. This was supplemented with the primary data collected from 82 sample villages.

District level information: At the district level, information was collected from various government departments. These included, the Directorate of Economics and Statistics, the 'Planning and Statistics Department' and the office of the Registrar of Cooperative Societies of the Government of Karnataka.

\section{Empirical findings}

Our household sample comprised of two broad groups of households: cooperative households $(\mathrm{CH})$; and non cooperative households $(\mathrm{NCH})$. A pertinent question was whether the representative sample should comprise of only the eligible (cooperative) households or the full sample. The argument in favour of the former is that the programme covers only cooperative households and therefore the impact of the factors affecting membership can be more meaningfully captured by the regression based on the censored sample. However, the participation in cooperative societies itself is voluntary, the possibility of unobservable self selection bias could not therefore be ruled out. Any regression based only on the sample of cooperative members will not capture the systematic difference between the two groups. If the regression is based only on the cooperative households then it is necessary to adjust it for the selection bias. Since we do not have any idea of the bias involved, we used both, the 
censored and the full sample in alternative specifications. The logit model estimations show a relatively good fit of the model, expressed by Chi-squared statistics in both the specifications (Table 2). The results are also found to be consistent and stable. In what follows, we discuss the results.

Gender equity: Our logistic regressions reveal that the probability of enrolling into the CBHI scheme was gender neutral. The variable Sh_Female turns insignificant in all the specifications of enrollment (including renewals). This indicates that the programme offers equal access to health care services to all irrespective of the gender. Interestingly however, the variable turns positive and significant in the estimation of beneficiaries' function indicating that the women are likely to be the major beneficiaries of the programme. The programme has gender positive effects in terms of the distribution of benefits.

Evidence suggests that in developing countries females are more susceptible to illness than men. Nutritional status of women and girls is compromised by unequal access to food, by heavy work demands, and by special nutritional needs (such as for iron). Furthermore, they are often trapped in a cycle of ill health exacerbated by childbearing, exposure to heavy smoke from kitchen fires, and hard physical labor, especially in agricultural areas. Despite their serious health problems they do not get adequate levels of preventive care. The consequences of women's unfavorable status in inherently inequitable social system prevalent in most developing countries include discrimination in the allocation of household resources, such as food, health care and education. Women's health and nutritional status is thus inextricably bound up with social, cultural, and economic factors that influence all aspects of their lives. Therefore, women comprise the key stakeholders in health policy debates and are the most vulnerable section of the society. The focus of any social health insurance scheme should therefore be to ensure that the scheme provided is just as attractive to women as it is to 
the men and that it is effective in attracting their participation and providing health access. The Yeshasvini health care programme is an opportunity for the rural women to access quality health care services at low contribution.

Social equity: While the programme is equitable in terms of female participation, it is inequitable among different social groups. After controlling for the socio economic characteristics of households, H_SC turned significant with a negative sign in all the specifications of enrolment, renewal of enrolment and utilisation after controlling for other household and location specific characteristics. This implies that there is a problem of social exclusion in enrollment and utilisation. The programme enrollment is biased in favour of the empowered classes of the society. Since independence, there has been political and social mobilisation of SCs in India. However, this mobilisation has failed to translate into positive change in the social sector for this excluded population. This is reflected in the enrollment process of the programme.

Education, access to information (access_tv, access-paper) and membership of self help groups, are found to be empowering factors that increase the likelihood of joining the programme and renewing membership. Thus the population groups that suffer from social vulnerabilities in terms of lack of education, access to information and community groups have lower probability of joining the programme. The programme is socially inequitable in that sense.

Utilisation of the programme however is influenced only by the levels of education; other variables are not significant. Thus, social inequities are less skewed in terms of the distribution of benefits. 
Economic equity: Enrollment into the programme and renewal of enrolment, both are found to be inequitable in economic terms as well. The variable hholdasset is significant with a positive sign in all the specification of the logit model indicating that enrolment remains disproportionately in favour of the wealthier classes. Income turns insignificant though.

Interestingly, both income and wealth related factors turned insignificant in the beneficiaries' equation. This means that there are no significant differences in the income levels of yeshasvini beneficiaries and non beneficiaries. Apparently, while a well off household is more likely to become a member, a beneficiary is not necessarily economically better off than his non Y-member counterpart seeking surgery. Most studies while analysing financial protection aspect of $\mathrm{CBHI}$ focus on membership and its relationship with income, and on finding a positive relationship between income and the probability of becoming a member conclude that the scheme does not reach the vulnerable. Our analysis also finds a positive relationship between income and the probability of enrolment. However, it reveals at the same time that benefits, which represent an outcome of membership, do not necessarily go to wealthier households.

Health equity: chron_health also turns significant in all the equations. This implies that poorer the health status of household members, the greater is the likelihood of the household to join the programme. Technically, this is termed as 'adverse selection'. But in practice, the objective of the scheme is to provide equitable access to health care on the basis of need; if people with the greatest needs are joining the scheme and increasing their use of services that is consistent with this objective of equity. However, this raises concerns about the future sustainability of the programme. Health service utilisation increases with age, a commonly reported finding. As age increases, there is increasing likelihood of experiencing an episode 
of ill-health, and this greater health need accounts for the increased levels of utilisation among individuals aged over 60 .

\section{INSERT TABLE 2 HERE}

Locational equity: Location- specific vulnerabilities are expected to increase risk aversion. Insurance therefore can promote locational equity. Our analysis shows that both, the membership and the renewal of membership, are positively related with locational vulnerabilities as represented by D-hlthinfra and V_naturalcdn. Thus, the households located in districts with poor government health infrastructure are more likely to join the programme. Location specific natural disadvantages also affect individual preferences to enroll with the programme. This implies that the programme is doing well in reaching the areas where government health facilities are poor and the probability of natural calamity is higher. The programme is thus covering the most vulnerable groups of the rural population and to that extent, it is equitable. However, enrolment into the programme ( current and renewals) is found to be negatively related with poverty, poor living conditions, and distances from the government health care facilities and is positively related with transport facilities. By disproportionately favouring the people in better off villages and districts it exacerbates inequities. Thus the net effects of the enrolment into the programme on locational vulnerabilities remain uncertain. When viewed from the perspective of beneficiaries however, the programme is neutral with regard to locational vulnerabilities. It does not disproportionately favour the people in well off districts. Clearly the programme is more equitable in terms of the distribution of actual benefits.

\section{Conclusion}

This study analyses whether micro health insurance programmes can serve as an effective instrument in providing health security to the most vulnerable sections of the society. More specifically it examines how equitable is enrolment, renewal, and utilisation of communitybased health insurance? While doing so, it focuses on one of the largest and the most innovative CBHI programmes in India: Yeshasvini health care programme. Data was collected using a questionnaire that was administered to 4109 respondents in rural Karnataka selected by stratified random sampling. Our results based on logit models reveal that while 
enrolment and renewal of enrolment are inequitable, there is little inequity in utilisation of services.

Yeshasvini is one of the most innovative and successful CBHI programmes in India. It has the potential to increase access of the most vulnerable groups of the population to health care and provide them financial protection (Aggarwal 2010). But nevertheless, it could not fully resolve the issue of equality. In general, one can suggest that efforts need to be made to increase the number of enrolees, so as to increase the pool of funds and risks. Information dissemination is an important aspect of the scheme. A well designed marketing package may be employed to promote enrolment and renewal of enrolment. Besides, strategies should be adopted to increase levels of trust by improving

- quality of care (through strategic purchasing);

- transparency and accountability among those managing the scheme;

- recourse to justice to punish fraud; and

- community participation in the programme management.

More importantly however, it indicates that CBHI programmes are useful in themselves, but no substitute for hospitals and hospital networks that can respond to the needs of the most vulnerable sections of the population. The National Rural Health Mission (NRHM) was launched in 2005 by the Government in India to improve the availability of and access to quality healthcare by people, especially for the vulnerable population. An early impact evaluation of the programme (Gill,2009) however indicates that there are many problems in its implementation, so that delivery is far from what is ought to be. These problems need to be overcome with the necessary political will and commitment at all levels.

\section{References}

Aggarwal, A. (2010), Impact evaluation of India's 'Yeshasvini' community-based health insurance programme. Health Economics, 19: 5-35. 
Atim C. (1999), Social movements and health insurance: a critical evaluation of voluntary, non-profit insurance schemes with case studies from Ghana and Cameroon. Social Science and Medicine 48, $881-886$.

Besley T. 1989. The demand for health care and health insurance. Oxford Review of Economic Policy 5(1): 21-33.

Churchill C. (2006) Protecting the Poor: A Microinsurance Compendium, Geneva: ILO.

Criel B. \& M.P. Waelkens (2003) Declining subscriptions to the Maliando Mutual Health Organisation in Guinea-Conakry (West Africa): What is going wrong?, Social Science and Medicine 57 (2003), 42-48

De Allegri M., M. Sanon and R. Sauerborn (2006) “To enrol or not to enrol?": A qualitative investigation of demand for health insurance in rural West Africa Social Science \& Medicine 62, (6) , 1520-1527

Dror, D. and Ch Jacquier (1999) Micro-insurance: Extending Health Insurance to the Excluded, International Social Security Review (Geneva), ISSA, 1999,

Dror DM and AS Preker (2002): (ed) Social Reinsurance: A New Approach to Sustainable Community Health Financing, (Washington), World Bank \& ILO, 2002, xvii+518 pp.

Ekman B. (2004). Community-based health insurance in low-income countries: A systematic review of the evidence. Health Policy and Planning, 19, 249-270.

Gill, K. (2009) A Primary Evaluation of Service Delivery under the National Rural Health Mission (NRHM): Findings from a Study in Andhra Pradesh, Uttar Pradesh, Bihar and Rajasthan, Working Paper 1/2009 - PEO Planning Commission of India, May 2009

Hsiao (2001) Unmet Health Needs of Two Billion: Is Community Financing a Solution? Report Submitted to Working Group 3 of the Commission on Macroeconomics and Health

ILO (2005) India: An inventory of micro insurance schemes Community-Based Schemes Working Paper no. 2,

ILO (2006): India yeshasvini cooperative farmers health scheme social security extention intifatives in South Asia ILO 2006,

Jakab and Krishnan (2004) Review of the strengths and weaknesses of community financing. In A. S. Preker, \& G. Carrin (Eds.), Health financing for poor people: Resource mobilisation and risk sharing (pp. 53-118). Washington, DC: The World Bank.

Jakab and Krishnan (2001) Community involvement in health carefinancing: impact, strengths and weaknesses a synthesis of the literature. World Bank/HNP Discussion Paper. Washington, DC: World Bank.

Jowett, M., P. Contoyannis and N. D. Vinh (2003). "The impact of public voluntary health insurance on private health expenditures in Vietnam." Social Science and Medicine 56(2): 333-42.

Jowett, M (2008) Matt Jowett (2008) Sustainable health financing in low income countries: does social capital offer any insights? April 2008

http://www.opi.org.uk/publications/documents/Socialcapitalandhealthfinancing_JowettApril2008.pdf 
Lin Feng-Teng (2009) Does the Risk Aversion Vary with Different Background Risk of Households? International Research Journal of Finance and Economics , Issue 34 (2009)

Kiwanuka-Mukiibi, P., Derriennic, Y., Karungi. G (2005) The Good Practice Model: Community Participation in Luweero District, Uganda., The Partners for Health Reformplus Project, Abt Associates Inc, Bethesda, MD.

Kuruvilla S, M. Liu (2007) Health security for the rural poor? A case study of a health insurance scheme for rural farmers and peasants in India. International Social Security Review 60(4): 3-21.

Meessen, B., Criel, B., Kegels, G. (2002) 'Formal pooling of health risks in sub-Saharan Africa: Reflections on the obstacles encountered', International Social Security Review, 55.

Mladovsky P, Mossialos E. (2008) A conceptual framework for community-based health insurance in low-income countries: social capital and economic development. World Development (2008) 36:590-607.

Onwujekwe et al. (2009) Is community-based health insurance an equitable strategy for paying for healthcare? Experiences from southeast Nigeria Health Policy 92 (2009) 96-102

Polonsky, J. et al. (2009) Equity in community health insurance schemes: evidence and lessons from Armenia, Bulletin of the World Health Organisation

Preker at al (2002): Effectiveness of community health financing in meeting the cost of illness Bull World Health Organ Vol. 80 no.2 Genebra. 2002

Radermacher R et al.( 2005) KarunaTrust, Karnataka, India. Series: Good and Bad Practices in Microinsurance, no. 19. Geneva: CGAP Working Group on Microinsurance; 2005.

Ranson M K. (2007) Equitable utilisation of Indian community based health insurance scheme among its rural membership: cluster randomised controlled trial BMJ, June 23, 2007; 334(7607): $1309-1309$

Ron (1999), NGOs in community health insurance schemes: examples from Guatemala and the Philippines. Social Science and Medicine 48, 939-950

Schneider P. (2004) Why should the poor insure? Theories of decisionmaking in the context of health insurance. Health Policy and Planning 2004;19(6):349-55.

Schmidt-Thomé P., Jarva J. (eds.), 2003: ESPON project 1.3.1 the spatial effect and management of natural and technological hazards in general and in relation to climate change 2nd Interim Report, August 2003, GTK, Espoo

Tabor, S.R (2006): community based health insurance and social protection policy social protection discussion paper series No. 0503.

Van Ginneken, W. (1999). Overcoming Social Exclusion. In Social Security for the Excluded Majority: Case Studies of Developing Countries, ed. W. van Ginneken, 1-36 Geneva: ILO.

World Health Organisation (2000). The World Health Report 2000: Health Systems: Improving Performance. Geneva: World Health Organisation. World Bank Group. 2000. 
World Health Organisation (2001) Macroeconomics and Health: Investing in Health for Economic Development Report of the Commission on Macroeconomics and Health, Chaired by Jeffrey D. Sachs

Zhang, L., H.Wang., L.Wang,. and W.Hsiao. (2006) 'Social capital and farmer's willingness-to-join a newly established community-based health insurance in rural China', Health Policy, 76, 233-42.

Table 1: Patterns of claimants by district and hospital (2004-07)

\begin{tabular}{|l|l|l|l|l|l|}
\hline District & $\begin{array}{l}\text { share of } \\
\text { top }\end{array}$ & $\begin{array}{l}\text { top } \\
\text { three }\end{array}$ & top 5 & $\begin{array}{l}\text { HH } \\
\text { index }\end{array}$ & No. \\
\hline District \\
\hline $2004-05$ & 14.87 & 33.38 & 47.92 & 670.5 & 27 \\
\hline $2005-06$ & 13.13 & 29.76 & 42.53 & & 27 \\
\hline $2006-07$ & 11.54 & 25.43 & 37.35 & 323.2 & 27 \\
\hline \multicolumn{7}{|l|}{} \\
\hline $2004-05$ & 27.12 & 50.80 & 69.70 & 1417.7 & 60 \\
\hline $2005-06$ & 24.76 & 40.43 & 53.98 & & 60 \\
\hline $2006-07$ & 23.87 & 37.34 & 48.07 & 829.5 & 79 \\
\hline Hosp Name & & & \\
\hline $2004-05$ & 9.81 & 17.94 & 24.78 & 254.1 & 148 \\
\hline $2005-06$ & 12.59 & 22.13 & 28.30 & & 160 \\
\hline $2006-07$ & 10.74 & 19.48 & 26.03 & 230.3 & 290 \\
\hline
\end{tabular}

Source: Based on FHPL data

Table 2: Logit estimations of the probability of enrolling, renewing and utilizing the programme

\begin{tabular}{|l|r|r|r|r|r|r|}
\hline & \multicolumn{2}{|l|}{ Sample of Cooperative households } & \multicolumn{3}{|c|}{ Full sample } \\
\hline Variable & Enrolment & $\begin{array}{r}\text { Renewal of } \\
\text { membership }\end{array}$ & Utilisation & Enrolment & $\begin{array}{r}\text { Renewal of } \\
\text { membership }\end{array}$ & Utilisation \\
\hline Chron_health & $0.205351^{\mathrm{a}}$ & $0.28371^{\mathrm{a}}$ & 0.240782 & $0.213358^{\mathrm{a}}$ & $0.290039^{\mathrm{a}}$ & 0.286547 \\
& $(2.69)$ & $(3.5)$ & $(1.26)$ & $(3.1)$ & $(3.68)$ & $(1.55)$ \\
\hline Age-dividend & 0.002079 & -0.00029 & & 0.001 & 0.000356 & \\
& $(-1.08)$ & $(-0.12)$ & & $(0.57)$ & $(0.16)$ & \\
\hline headage & & & $0.035462^{\mathrm{a}}$ & & & $0.036535^{\mathrm{a}}$ \\
& & & $(2.92)$ & & & $(3.27)$ \\
\hline sh_female & -0.14818 & 0.203141 & $1.398251^{\mathrm{c}}$ & -0.28732 & 0.093576 & $1.277904^{\mathrm{c}}$ \\
& $(-0.57)$ & $(0.69)$ & $(1.74)$ & $(-1.27)$ & $(0.34)$ & $(1.71)$ \\
\hline sc_grp & $-0.7004^{\mathrm{a}}$ & $-0.61464^{\mathrm{a}}$ & $-1.13899^{\mathrm{a}}$ & $-0.75175^{\mathrm{a}}$ & $-0.69427^{\mathrm{a}}$ & $-1.18738^{\mathrm{a}}$ \\
& $(-6.11)$ & $(-3.99)$ & $(-2.53)$ & $(-7.24)$ & $(-4.66)$ & $(-2.68)$ \\
\hline aveduyears & $0.141982^{\mathrm{a}}$ & $0.037442^{\mathrm{b}}$ & 0.035622 & $0.0823^{\mathrm{a}}$ & $0.049656^{\mathrm{a}}$ & $0.068074^{\mathrm{c}}$ \\
& $(-3.72)$ & $(2.28)$ & $(0.88)$ & $(6.11)$ & $(2.99)$ & $(1.7)$ \\
\hline
\end{tabular}




\begin{tabular}{|c|c|c|c|c|c|c|}
\hline access_paper & $\begin{array}{r}-0.08404^{b} \\
(-2.26)\end{array}$ & $\begin{array}{r}-0.09165^{b} \\
(-2.02)\end{array}$ & & $\begin{array}{r}-0.10225^{\mathrm{a}} \\
(-3.08)\end{array}$ & $\begin{array}{r}-0.10597^{\mathbf{b}} \\
(-2.41)\end{array}$ & \\
\hline access_tv & $\begin{array}{r}-0.0767^{\mathbf{c}} \\
(-1.76)\end{array}$ & $\begin{array}{r}-0.06488 \\
(-1.18)\end{array}$ & & $\begin{array}{r}-0.11038^{\mathrm{a}} \\
(-2.81)\end{array}$ & $\begin{array}{r}-0.09833^{\mathrm{c}} \\
(-1.84)\end{array}$ & \\
\hline membershg & $\begin{array}{r}0.157691^{\mathbf{b}} \\
(2.39)\end{array}$ & $\begin{array}{r}0.065381 \\
(0.88)\end{array}$ & $\begin{array}{r}-0.16761 \\
(-0.95)\end{array}$ & $\begin{array}{r}0.171098^{\mathrm{a}} \\
2.89\end{array}$ & $\begin{array}{r}0.087044 \\
(1.22)\end{array}$ & $\begin{array}{r}-0.15119 \\
(-0.84)\end{array}$ \\
\hline Annual_inc & $\begin{array}{r}0.092432 \\
1.23\end{array}$ & $\begin{array}{r}0.018317 \\
0.21\end{array}$ & $\begin{array}{r}-0.01091 \\
-0.06\end{array}$ & $\begin{array}{r}0.1879 \\
2.7\end{array}$ & $\begin{array}{r}0.152372^{\mathrm{c}} \\
1.82\end{array}$ & $\begin{array}{r}0.046913 \\
0.24\end{array}$ \\
\hline hh_wealth & $\begin{array}{r}0.23584^{\mathrm{a}} \\
(3.14)\end{array}$ & $\begin{array}{r}0.263417^{\mathrm{a}} \\
(3.32)\end{array}$ & & $\begin{array}{r}0.336971^{\mathrm{a}} \\
(5.00)\end{array}$ & $\begin{array}{r}0.32368^{\mathrm{a}} \\
(4.29)\end{array}$ & \\
\hline Concen_income & $\begin{array}{r}-2.70 \mathrm{E}-05 \\
(-1.17)\end{array}$ & $\begin{array}{r}-1.70 \mathrm{E}-05 \\
(-0.63)\end{array}$ & & $\begin{array}{r}-3.50 \mathrm{E}-05^{\mathrm{c}} \\
(-1.71)\end{array}$ & $\begin{array}{r}-2.60 \mathrm{E}-05 \\
(-1.00)\end{array}$ & \\
\hline V_wat_san & $\begin{array}{r}-5.66 \mathrm{E}-06 \\
(-0.49)\end{array}$ & $\begin{array}{r}2.45 \mathrm{E}-05^{\mathrm{c}} \\
(1.78)\end{array}$ & $\begin{array}{r}-0.26624 \\
(-0.99)\end{array}$ & $\begin{array}{r}-6.83 \mathrm{E}-06 \\
(-0.67)\end{array}$ & $\begin{array}{r}2.12 \mathrm{E}-05^{\mathrm{c}} \\
(1.67)\end{array}$ & $\begin{array}{r}-0.32946 \\
(-1.29)\end{array}$ \\
\hline V_hlthdistance & $\begin{array}{r}-0.03196 \\
(-0.55)\end{array}$ & $\begin{array}{r}-0.12809^{\mathrm{C}} \\
(-1.87)\end{array}$ & $\begin{array}{r}-0.25207 \\
(-1.39)\end{array}$ & $\begin{array}{r}-0.15594^{a} \\
(-3.08)\end{array}$ & $\begin{array}{r}-0.2102^{\mathrm{a}} \\
(-3.26)\end{array}$ & $\begin{array}{r}-0.3198^{\mathbf{c}} \\
(-1.82)\end{array}$ \\
\hline V_hlthinfra & & & $\begin{array}{l}-0.08953 \\
(-0.77)\end{array}$ & & & $\begin{array}{r}-0.10007 \\
(-0.89)\end{array}$ \\
\hline V_naturalcdn & $\begin{array}{r}0.041919 \\
(0.97)\end{array}$ & $\begin{array}{r}0.082117^{\mathrm{c}} \\
(1.88)\end{array}$ & & $\begin{array}{r}0.06901^{\mathbf{c}} \\
(1.77)\end{array}$ & $\begin{array}{r}0.103093^{c} \\
(2.5)\end{array}$ & \\
\hline Yesh_dis & & & $\begin{array}{r}-0.00782^{\mathrm{c}} \\
(-1.87)\end{array}$ & & & $\begin{array}{r}-0.00699^{\mathrm{c}} \\
(-1.74)\end{array}$ \\
\hline D_health_infra & $\begin{array}{r}-0.05231^{\mathrm{c}} \\
(-1.71)\end{array}$ & $\begin{array}{r}-0.06052^{\mathrm{c}} \\
(-1.67)\end{array}$ & & $\begin{array}{r}-0.08136^{a} \\
(-2.84)\end{array}$ & $\begin{array}{r}-0.08004^{b} \\
(-2.23)\end{array}$ & \\
\hline D_tpt & $\begin{array}{r}0.152201^{\mathrm{a}} \\
(3.11)\end{array}$ & $\begin{array}{r}0.134603^{\mathrm{a}} \\
(2.55)\end{array}$ & $\begin{array}{r}0.091721 \\
(0.6)\end{array}$ & $\begin{array}{r}0.020483 \\
(0.49)\end{array}$ & $\begin{array}{r}0.067954 \\
(1.35)\end{array}$ & $\begin{array}{r}0.123493 \\
(0.86)\end{array}$ \\
\hline hsize & $\begin{array}{r}0.024448 \\
(-1.35)\end{array}$ & $\begin{array}{r}0.037321^{\mathrm{c}} \\
(1.88)\end{array}$ & & $\begin{array}{r}0.0201 \\
1.15\end{array}$ & $\begin{array}{r}0.036624^{\mathrm{c}} \\
1.82\end{array}$ & \\
\hline D_pcy & & $\begin{array}{r}4.78 \mathrm{E}-05^{\mathrm{a}} \\
(3.66)\end{array}$ & $\begin{array}{r}4.65 \mathrm{E}-05 \\
(0.96)\end{array}$ & $\begin{array}{r}-5.84 \mathrm{E}-06 \\
(-0.67)\end{array}$ & $\begin{array}{r}4.25 \mathrm{E}-05^{\mathrm{a}} \\
(3.61)\end{array}$ & $\begin{array}{r}5.11 \mathrm{E}-05 \\
(1.13)\end{array}$ \\
\hline D_f_mem_gp & & & $\begin{array}{r}0.182434^{\mathrm{c}} \\
(1.83)\end{array}$ & & & $\begin{array}{r}0.203465^{\mathbf{b}} \\
(2.14)\end{array}$ \\
\hline D_panchay_ & $\begin{array}{r}-0.25307 \\
(-0.37)\end{array}$ & $\begin{array}{r}-0.26049 \\
(-0.33)\end{array}$ & & $\begin{array}{r}1.049763^{\mathrm{c}} \\
(1.68)\end{array}$ & $\begin{array}{r}0.541192 \\
(0.7)\end{array}$ & \\
\hline V_copop & $\begin{array}{r}5.778508 \\
(0.28)\end{array}$ & $\begin{array}{r}102.317^{\mathrm{a}} \\
(4.49)\end{array}$ & $\begin{array}{r}116.0558^{\mathrm{c}} \\
(1.69)\end{array}$ & $\begin{array}{r}30.74835^{\mathrm{c}} \\
(1.67)\end{array}$ & $\begin{array}{r}114.3783^{\mathrm{a}} \\
(5.21)\end{array}$ & $\begin{array}{r}167.355^{\mathrm{a}} \\
(2.62)\end{array}$ \\
\hline _cons & $\begin{array}{r}-0.69997 \\
(-0.92)\end{array}$ & $\begin{array}{r}-2.28857^{\mathrm{a}} \\
(-2.6)\end{array}$ & $\begin{array}{r}-4.0531^{\mathrm{c}} \\
(-1.89)\end{array}$ & $\begin{array}{r}-2.69936^{\mathrm{a}} \\
(-3.98)\end{array}$ & $\begin{array}{r}-3.51732^{\mathrm{a}} \\
(-4.17)\end{array}$ & $\begin{array}{r}-5.28689^{b} \\
(-2.47)\end{array}$ \\
\hline LR statistics & 229.56 & 177.78 & 36.14 & 444.16 & 296.01 & 49.57 \\
\hline $\mathrm{NOB}$ & 2756 & 2756 & 395 & 3772 & 3772 & 483 \\
\hline
\end{tabular}

